\title{
Endoscopic Endonasal Resection of Rathke Cleft Cyst with Xanthogranulomatous Change: Two- Dimensional Operative Video
}

\author{
${ }^{1}$ Department of Neurosurgery, Stanford Medical Center, Stanford, \\ California, United States \\ ${ }^{2}$ Department of Neurological Surgery, University of Miami Miller \\ School of Medicine, Miami, United States \\ ${ }^{3}$ Department of Pathology, Santa Clara Valley Medical Center, San \\ Jose, California, United States \\ ${ }^{4}$ Department of Physical Medicine and Rehabilitation, Rehabilitation \\ Research Center, Santa Clara Valley Medical Center, San Jose, \\ California, United States
}

Michael Zhang ${ }^{1}$ Anil K. Mahavadi ${ }^{2} \quad$ Michael L. Deftos $^{3} \quad$ Arshad Ali $^{4}$ Harminder Singh ${ }^{1}$

\begin{abstract}
Address for correspondence Harminder Singh, MD, Department of Neurosurgery, Stanford University School of Medicine, 300 Pasteur Drive, MC 5327, Stanford, CA 94305 (e-mail: harman@stanford.edu).
\end{abstract}

J Neurol Surg B Skull Base 2022;83(suppl S3):e655-e656.
Abstract
Keywords
- endoscopic endonasal
- pediatrics
- pituitary
- Rathke's cleft cyst
- xanthogranuloma

Objective Sellar xanthogranulomas (XGAs) are a rare pathological subtype of hypophysitis reflecting a degenerative process of Rathke's cleft cyst with predilection in young adults. While the histological features have been described, there is limited discussion on the technical expectations in surgical management. We present the clinical, radiographic, and surgical features of the third literature-reported XGA in the pediatric population.

Setting The patient was a 17-year-old boy who first identified by ophthalmologically confirmed peripheral vision loss. Subsequent endocrine workup identified delayedonset puberty and hypopituitarism. Magnetic resonance imaging (MRI) showed a nonenhancing 2.6-cm T1 and T2 sellar-based hyperintense mass with suprasellar extension and mass effect on the optic chiasm. A small T1 hypointense encased nodule was also seen (- Fig. 1). Consent for resection was obtained.

Results Intraoperatively the tumor was firm and adherent, requiring piecemeal removal. Radiofrequency ablation enabled ergonomic debulking and minimize thermal injury (-Fig. 2). ${ }^{1}$ We used initial settings of $25 \mathrm{~W}$, equivalent to $55 \mathrm{~W}$. A cystic component with motor oil-like fluid was encountered and decompressed. The tumor was notably very adherent to the optic nerve and infiltrated the stalk, requiring its received

May 7, 2020

accepted after revision

January 10, 2021

published online

May 12, 2021

www.thieme.com/skullbasevideos

www.thieme.com/jnlsbvideos

DOI https://doi.org/

$10.1055 / \mathrm{s}-0041-1727128$. ISSN 2193-6331.

\footnotetext{
(C) 2021. The Author(s).

This is an open access article published by Thieme under the terms of the Creative Commons Attribution-NonDerivative-NonCommercial-License, permitting copying and reproduction so long as the original work is given appropriate credit. Contents may not be used for commercial purposes, or adapted, remixed, transformed or built upon. (https://creativecommons.org/ licenses/by-nc-nd/4.0/) Georg Thieme Verlag KG, Rüdigerstraße 14, 70469 Stuttgart, Germany
} 
truncation. Closure was achieved by fat graft dead space plugging, fascia lata underlay, Medpor gasket seal, and nasoseptal flap.

Conclusion Pathology confirmed dense fibrous tissue with features of chronic inflammation, cholesterol clefts, hemosiderin pigment, multinucleate giant cells, and foamy macrophages. Additional cyst wall sampling identified squamous and ciliated epithelial lining, collectively consistent with Rathke's cleft cyst and xanthogranulomatous reaction. These lesions can undergo surgical cure with resection, most commonly by transsphenoidal approach.

The link to the video can be found at: https://youtu.be/S2n5iQ3aFgc.
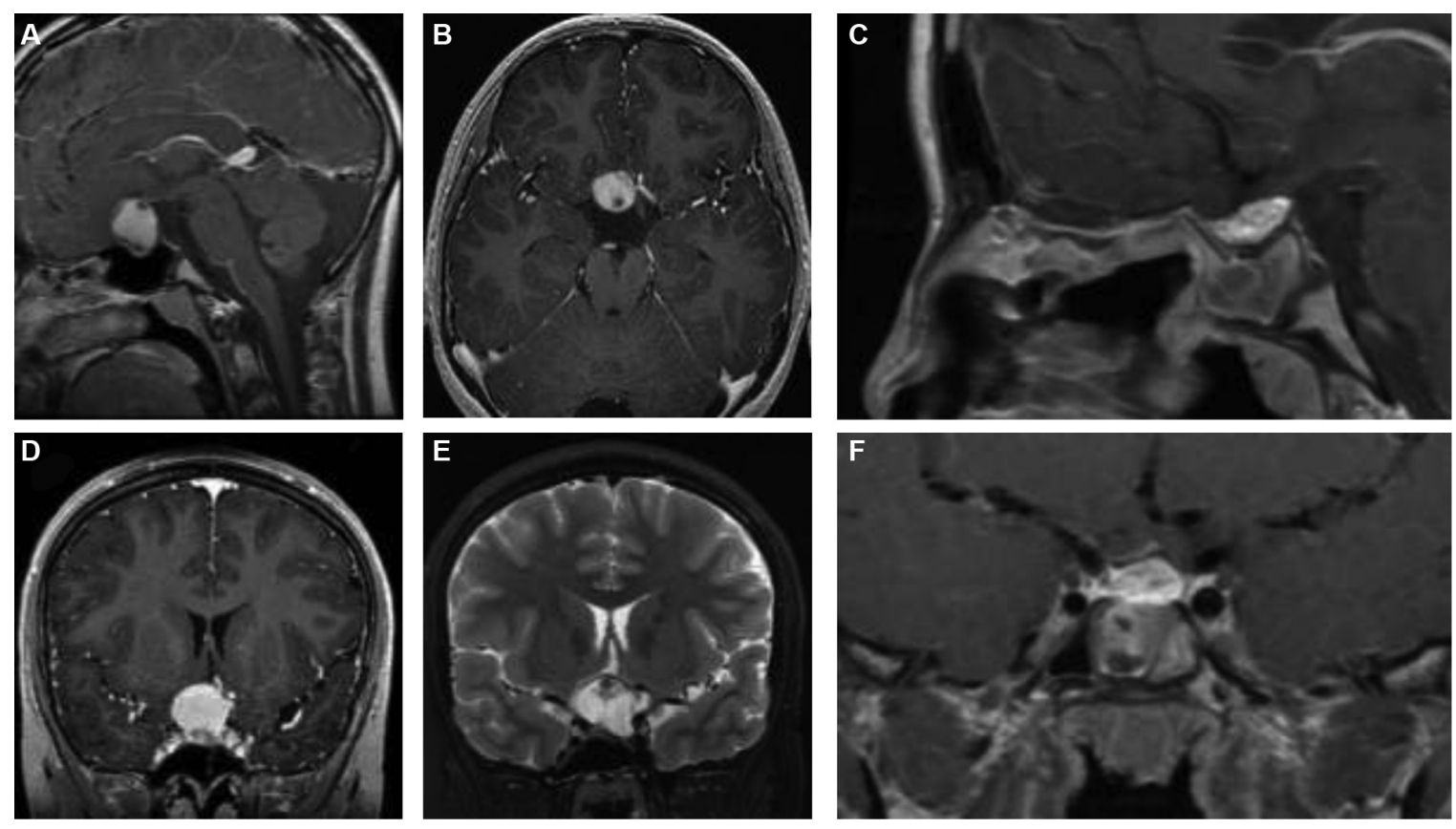

Fig. 1 (A-C) Preoperative T1-gadolinium enhanced sagittal, axial, and coronal sequences. (D) Preoperative T2 coronal sequence. (E, F) Postoperative T1 gadolinium-enhanced sagittal and coronal sequences.
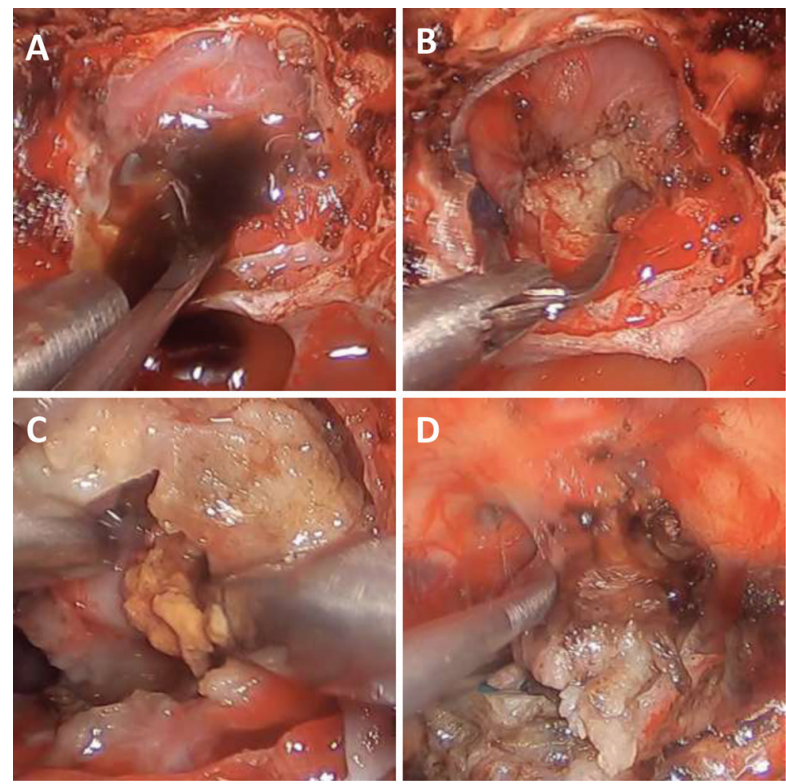

Fig. 2 Intraoperative images of tumor texture and behavior, including (A) motor oil drainage, (B) thick, fibrous cystic capsule, (C) cholesterol granuloma, and (D) adhesion to the optic chiasm.

\section{Funding}

This research did not receive any specific grant from funding agencies in the public, commercial, or not-forprofit sectors.

Conflict of Interest

None declared.

\section{References}

1 Essayed WI, Radhounane K, Schwartz TH, Singh H. Instrumentation. In: Singh H, Greenfield JP, Anand VK, Schwartz TH, eds. Pediatric Endoscopic Endonasal Skull Base Surgery. 1st ed. New York, NY: Thieme Medical Publishers Inc.; 2020 